\title{
Cambios en el paisaje de menorca desde 1975 hasta 2010 mediante teledetección
}

\section{Changes in the landscape of menorca from 1975 to 2010 by remote sensing}

DOI: $10.46814 /$ lajdv3n5-052

Recebimento dos originais: 01/09/2021

Aceitação para publicação: 26/10/2021

\author{
Dr. Emilio Ramírez-Juidías \\ University of Seville (Spain) \\ Corresponding author \\ E-mail: erjuidias@us.es \\ Msc. Francisco Víquez-Urraco \\ Andalusian Government (Spain) \\ E-mail: francisco.viquez@juntadeandalucia.es
}

\section{RESUMEN}

La isla de Menorca, Reserva de la Biosfera, ha originado una fuerte atracción turística a consecuencia de su gran riqueza paisajística. En este estudio, se analizaron 265 imágenes Landsat procedentes del United States Geological Service para el periodo 1975-2010, todas examinadas y clasificadas en un determinado lapso de tiempo con el fin de poder caracterizar correctamente el desarrollo territorial espacial y temporalmente. Los resultados muestran como entre 1975 y 1990 no existe desarrollo del paisaje. Entre 1990 y 2000, hay un gran aumento de la vegetación a consecuencia de la protección recibida por la Unesco. En el periodo 2000-2010, es evidente el efecto del clima en el desarrollo del paisaje.

Palabras clave: Menorca, imágenes teledetectadas, paisaje sostenible.

\begin{abstract}
The island of Menorca, Reserve of the Biosphere, has created a strong tourist attraction due to its rich landscape. In this research, 265 Landsat satellite images from the United States Geological Service were analyzed or the 1975 to 2010 eriod, each of which was examined and classified in a certain period of time in order to characterize right way the territorial development both spatially and temporally. The results show how between 1975 and 1990 there is virtually no landscape development. Between 1990 and 2000, there is a strong increase of vegetation as a result of the protection received by UNESCO. In the period 2000-2010, it was evident the effect of climatic factors in the landscape development.
\end{abstract}

Keywords: Menorca, remotely sensed images, sustainable landscape. 


\section{INTRODUCCIÓN}

La isla de Menorca es un espacio insular de pequeñas dimensiones con un alto grado de conservación de sus recursos naturales y paisajísticos, hecho que permitió su declaración como Reserva de la Biosfera el 8 de octubre de 1993.

La sostenibilidad ambiental ${ }^{1}$, definida como el conjunto de políticas y procesos encaminados a mantener un nivel de desarrollo adecuado que no ponga en peligro los recursos naturales existentes, es un concepto complejo, ya que depende del criterio que se escoja para determinar el momento en el que un nivel de desarrollo determinado no pone en peligro la pervivencia de los recursos existentes en un espacio geográfico dado. En este sentido, y en las últimas décadas, Menorca ha experimentado un profundo desarrollo normativo conducente a la elaboración de un Plan Territorial Insular (PTI), aprobado definitivamente el 25 de abril de 2003 por el Consell Insular de Menorca, gracias al cual el paisaje tiene una gran importancia tanto como recurso, como patrimonio ${ }^{2}$.

El crecimiento relativo de población urbana en la isla de Menorca $^{3}$, ha sido del 73,2\% entre 1998 y 2010, lo que ha dado lugar a una continua transformación del paisaje tradicional agrario con el fin de crear nuevas zonas urbanizadas. Éste crecimiento constante ha ido provocando el agotamiento de los recursos agrarios de los que se abastecían aquellas áreas rurales que, poco a poco, han sido absorbidas por el tejido urbano, dando como resultado una incesante migración del medio rural al urbano a consecuencia del rápido y consecuente crecimiento económico. Esto, que puede verse como una ventaja desde el punto de vista de crecimiento y desarrollo de la isla, puede convertirse en uno de los principales obstáculos para lograr mantener el actual desarrollo urbano sostenible (DUS) en Menorca. A este respecto, sería interesante que las políticas destinadas a mejorar los problemas de movilidad, de desarrollo sostenible, de calidad de vida, de competitividad urbana y de marketing estratégico constituyeran un nuevo marco de referencia ${ }^{4}$.

Varios estudios analizan la expansión urbana de Menorca. Desde el punto de vista formal ${ }^{5}$, el crecimiento urbano de Menorca presenta una forma difusa e irregular, a consecuencia principalmente de la dispersión de los principales núcleos litorales con elevada concentración, dando lugar a una diseminación de viviendas a lo largo del litoral debido a la expansión del turismo residencial mediante la ocupación de suelo rústico. Éste proceso ha tenido como resultado la aparición de una serie de islas dispersas por el territorio, con un carácter social propio independiente de los sectores urbanos contiguos y que tiene su origen en las dinámicas propias locales y particulares que dan lugar a su desarrollo y colonización.

En otro orden de temas, Menorca está transformando parte del patrón típico del archipiélago balear, basado en la compacidad y la drástica separación campo-ciudad, por otro más descentralizado ${ }^{6}$,

${ }^{7}$. En un primer momento, la conformación del modelo metropolitano de la urbe menorquina supuso la 
materialización de ciudades suburbanas, alrededor de las principales zonas habitadas, con alto índice de densidad edificatoria, que albergaban una parte importante de la industria. A su vez, en el área central permanecía la mayor parte de las funciones terciarias. Este modelo desequilibrado demandaba una importante movilidad de la población, debido a la necesidad de los desplazamientos centroperiferia por motivos de trabajo y de satisfacción de gran parte de los servicios personales.

Actualmente, y tras ser declarada Reserva de la Biosfera en 1993, el nuevo modelo de dispersión de la actividad por el territorio menorquín ha generado estructuras urbanas cada vez más complejas que exigen la articulación de espacios cada vez más desconectados y fragmentados. La descentralización de equipamientos y empresas (universidades, parques tecnológicos y empresariales, etc.) si bien tiende a compensar los déficits de la periferia, característicos del modelo anterior, incrementa la demanda de movilidad, lo que ha supuesto la necesidad de construcción de una extensa red de carreteras y autovías urbanas por todo el territorio.

Aunque el análisis de los cambios de uso del suelo (CUS) así como la evaluación de la sostenibilidad en el territorio menorquín, han sido tratados en mayor o menor medida, menos atención ha sido prestada en el estudio del impacto que los CUS han provocado sobre el DUS. De hecho, muy pocas publicaciones tratan la relación existente entre los CUS y el DUS, aunque de forma general, pero ninguna de ellas se centra en la isla de Menorca. Es por ello que en el presente artículo el objetivo principal será utilizar, de manera conjunta, imágenes teledetectadas y sistemas de información geográfica (SIG) para lograr obtener la citada relación y, poder explicar los cambios acaecidos en el paisaje menorquín durante los últimos 40 años desde el punto de vista de la sostenibilidad, siendo, de crucial importancia para tal fin, centrarse en el desarrollo histórico de la isla, ya que de su evolución a lo largo del tiempo depende la notable conservación actual del paisaje agrario y natural de Menorca.

\section{MATERIALES Y MÉTODOS}

\section{1 ÁREA DE ESDTUDIO}

La isla de Menorca, a lo largo de su historia, ha estado sometida a una continua transformación, lo que le ha permitido adaptarse de manera sistemática al devenir de los tiempos, pero siempre manteniendo la base de los asentamientos preexistentes. Los primeros pobladores llegaron por mar en la Edad del Bronce ${ }^{8}$, posiblemente a raíz de la expansión de los pueblos de la cuenca oriental del Mediterráneo en busca del cobre y el estaño de occidente.

A una primera etapa de civilización primitiva, sucedió otra muy brillante conocida como talayótica $^{6}$, caracterizada por grandes construcciones ciclópeas afines a las de Mallorca, Cerdeña y Malta, pero de gran originalidad tipológica. Esta cultura talayótica perduró aun después de la conquista 
romana, aunque tuvo contactos superficiales con fenicios, griegos y cartagineses, siendo a estos últimos la atribución de la fundación de Mago, la actual Mahón ${ }^{8}$.

A partir del 122 a.C., y gracias a la romanización, el contacto con el exterior se hizo cada vez más patente, lo que originó la aparición de pequeños núcleos poblados más o menos rudimentarios, tales como Damma, la actual Ciudadela ${ }^{8}$. Posteriormente, tanto la llegada del cristianismo (hacia el siglo V), como la conquista vándala (hacia el año 427), desconectaron a Menorca del resto del mundo, lo que permitió el inicio de una etapa de extremo aislamiento que duraría hasta el año 900 de nuestra era.

Hay que tener presente que, desde el 902 hasta el 1287, no hay información suficiente que permita suponer que los musulmanes favorecieran el contacto con el exterior ${ }^{6}$, por lo que la explotación de los recursos agrícolas y ganaderos era la única fuente comercial y de alimento.

En 1232, tres años después de la reconquista de Mallorca por Jaime I, la Menorca musulmana se hizo tributaria de Aragón y algunos años después, en 1287, en el contexto de expansión mediterránea de la Corona de Aragón, se procedió a su repoblación a manos de Alfonso el Franco ${ }^{8}$.

La Menorca catalana gozó en parte y por breve tiempo del esplendor náutico catalán y de cierta prosperidad ganadera, principalmente lanar, pero a partir de finales del siglo XIV se inició una fuerte decadencia económica y demográfica, que alcanzó caracteres patéticos en los siglos XV y XVI, al unirse a la miseria las luchas sociales entre la aristocracia y el campesinado, entroncadas con las similares producidas en Mallorca y las frecuentes incursiones piratas que, tras los saqueos de Mahón en 1535 y Ciudadela en 1558, amenazaron con la total despoblación de la isla ${ }^{6}$ y .

En el siglo XVII, de lenta recuperación económica y demográfica, la estructura agraria predominante era latifundista con ganadería extensiva, muy similar al paisaje rural musulmán. En dicha época la ciudad de Ciudadela disfrutó de una gran pujanza, lo que produjo una proliferación de la estructura urbana sobre la rústica como consecuencia del aumento del número de iglesias y palacios ${ }^{6}$. En lo referente al siglo XVIII, la presencia inglesa en la isla, legalizada por el Tratado de Utrecht en 1713, dio un fuerte impulso a la economía insular, especialmente a la marina, lo que hizo de Mahón un emporio de comerciantes y corsarios, mientras que Ciudadela, la capital medieval de la isla y reducto aristocrático y clerical, quedaba fosilizada dentro de sus murallas ${ }^{8}$.

La pujanza marítima de Mahón se prolongó en el siglo XIX, aún después de la reincorporación de definitiva de la isla a España en 1802, representando la marina mahonesa un importante papel en el comercio cerealista del Mar Negro. Posteriormente, en 1820, las leyes proteccionistas que detuvieron dicho comercio dieron al traste con la marina mahonesa y con la economía de la isla, que inició una triste etapa provinciana. A finales del siglo XIX, el modesto tejido industrial, enfocado principalmente a la producción de calzado y bisutería, fue suficiente como para reanimar la economía menorquina. 
Tal y como especifica [6], la incorporación de mano de obra en el nuevo sector industrial del siglo XIX, tuvo como consecuencia inmediata un déficit laboral de grandes dimensiones en el ámbito rural. A raíz de esto, y debido a los bajos salarios pagados a los trabajadores del campo, la ganadería, que en tiempos difíciles perdió significación a favor del cultivo de cereal, volvió a ser predominante. El ganado vacuno empezó a ganar importancia frente al ovino, lo que estimuló la creación de una industria quesera que, con el tiempo, fue ganando presencia e importancia en la isla. La consecuencia inmediata de todo esto se vio reflejada en el siglo XX, ya que el campo menorquín se especializó íntegramente en el ganado vacuno, con el práctico total abandono de otras prácticas agrícolas y ganaderas, traducido en una baja presión rural gracias al desarrollo de la actividad industrial y comercial alternativa.

Este hecho, que podría ser considerado como un inconveniente, ha sido realmente una ventaja para la isla, ya que la presencia de una economía industrial poco dependiente de la base territorial, ha dado como resultado una notable conservación del paisaje agrario y natural de Menorca.

Tras el 8 de octubre de 1993, así como posteriormente con la aprobación definitiva del PTI se consiguió dotar a la isla de una mejora considerable en las comunicaciones urbanas e interurbanas tanto por carretera como en ferrocarril, ofreciendo una visión de neo-isla, totalmente adaptada a los posibles cambios que pudieran surgir en un futuro, brindando al visitante un sinfín de posibilidades de desplazamiento, centros comerciales, áreas verdes, lugares de ocio, monumentos, etc.. Actualmente, y gracias a la construcción de nuevas infraestructuras de comunicación, así como a la gestión sostenible de la arquitectura en la trama urbana insular, la isla se combina en un complejo entramado de superposiciones, dando lugar a un paisaje que se adapta a los momentos socio-económicos imperantes en cada época, y que permanece a lo largo del tiempo.

\subsection{DATOS Y METODOLOGÍA}

En el presente estudio, un total de 265 imágenes Landsat procedentes del archivo Earth Explorer del United States Geological Service (USGS) fueron obtenidas para el periodo de 1975 a 2010, único espacio de tiempo en el que existen imágenes satélite de calidad y número suficiente como para llevar a cabo la presente investigación. Cada una de las imágenes fue examinada y clasificada en un determinado lapso de tiempo (1975/1990, 1990/2000, 2000/2005 y 2005/2010) con el fin de caracterizar de manera idónea los cambios en el paisaje de Menorca. Todas las imágenes (Path 211 Row 32 "WRS-1" y Path 196 Row 32 "WRS-2") fueron adquiridas durante el mes de febrero de 2013. Un procesado, posterior a la clasificación efectuada con anterioridad, fue necesario para evitar que ciertos detalles, caso de las sombras, fueran clasificadas como vegetación. La superficie de Menorca fue calculada con el uso del SIG Ilwis mediante la multiplicación del número de píxeles de cada 
imagen, por la resolución espacial de la imagen satélite original (30 m para Thematic Mapper "TM" y Thematic Mapper Plus “ETM+” y 79 m para Multispectral Scanner "MSS”).

Todas y cada una de las imágenes satélite fue mejorada, y posteriormente mediante el uso del algoritmo del vecino más cercano, se logró mantener sin cambios el brillo original de los valores de los píxeles $^{9 \text { y } 10}$.

Con el fin de detectar cambios en las superficies reflectantes que conforman el área de estudio, se realizó una corrección radiométrica utilizando para ello el método especificado por [11]. Posteriormente, y con la ayuda del SIG Ilwis, se llevó a cabo un proceso de superposición de capas Web Map Service (WMS) procedentes de la Infraestructura de Datos Espaciales de las Islas Baleares (IDEIB), con el único fin de comprobar la coherencia del análisis efectuado mediante las imágenes satélite.

En otro orden de temas, se realizó una profunda revisión bibliográfica destinada a determinar la posible existencia de un registro temporal de datos climáticos, lo suficientemente amplio y significativo, de Menorca como para poder obtener unos resultados, discusión y conclusiones coherentes con la presente investigación. A este respecto la información suministrada por [12] fue de enorme importancia.

\section{RESULTADOS Y DISCUSIÓN}

De acuerdo con [12], la isla de Menorca posee una temperatura media anual en torno a los 16,8 ${ }^{\circ} \mathrm{C}$ (Fig. 1), que junto con su precipitación media de $599 \mathrm{~mm}$ (Fig. 2), concentrada entre los meses de septiembre a mayo, así como sus cerca de 2694 horas de sol al año, la convierten en uno de los principales lugares de visita turística de todo el mundo, no sólo por sus condiciones climáticas, sino también por su gran oferta paisajística, monumental, hotelera y de restauración. 
Figura 1- Datos termométricos de Menorca para el periodo de 1971 a 2000 (Nota: Tmed = temperatura media, TmM = temperatura media de las máximas, Tmm = temperatura media de las mínimas).

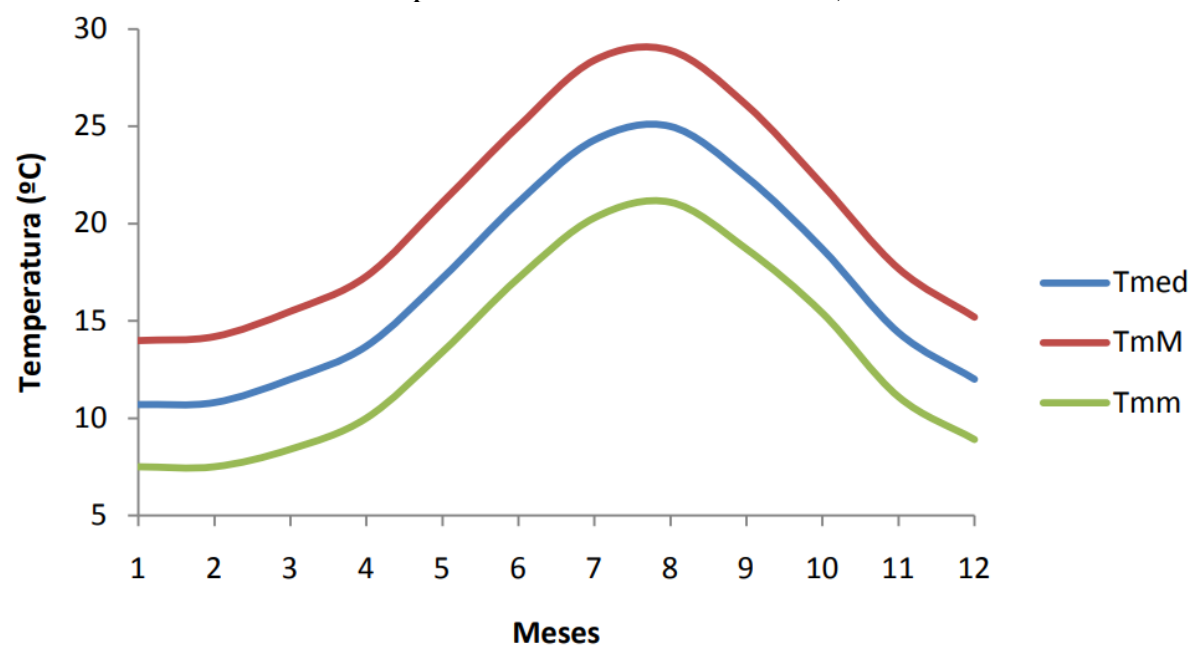

Figura 2- Datos de precipitación de Menorca para el periodo de 1971 a 2000 (Nota: Pmed = precipitación total media).

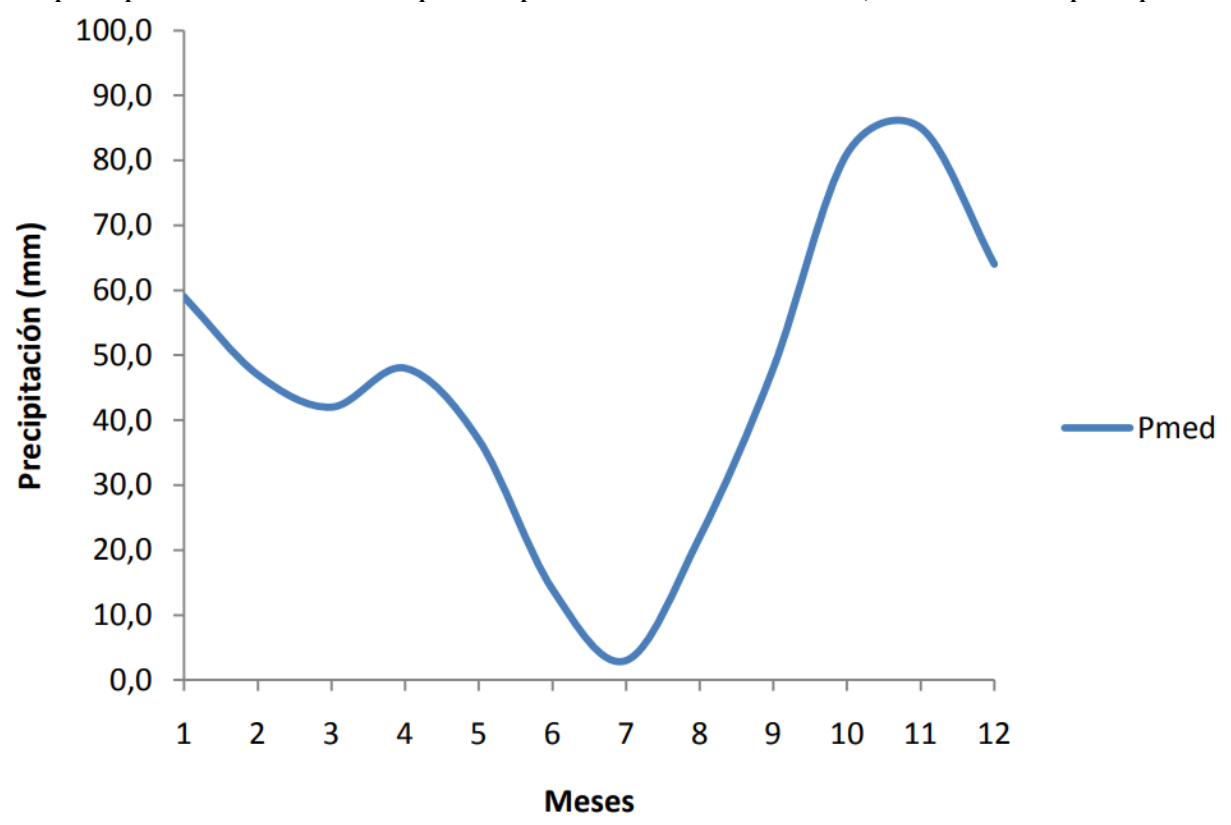

En otro orden de temas, los CUS producidos en el territorio menorquín han sido un reflejo fiel de su tipo de crecimiento difuso, a saltos, dando lugar a una serie de áreas inconexas con los diferentes núcleos urbanos existentes que poco a poco han sido incorporadas a los mismos, haciendo posible el incremento de la demanda de movilidad y aparición de nuevas infraestructuras de transporte entre otras, lo que ha permitido a Menorca ser cada vez más sostenible.

El crecimiento del área construida de Menorca se encuentra en relación directa con el poblacional, tal y como se desprende de [13]. Desde la segunda mitad del siglo XX, la fragmentación del territorio ha ido desapareciendo a medida que nos hemos ido acercando a 2010, gracias sin duda a las políticas emprendidas por el gobierno local en materia de sostenibilidad, lo que ha hecho que la extensión territorial de la isla, alrededor de $702 \mathrm{~km}^{2}$ de superficie, sea integrada en su mayoría por una 
zona de gran valor paisajístico, complementada con las áreas urbanas e infraestructuras de transporte de gran nivel internacional.

Desde principios del siglo XX, la población de Menorca (Fig. 3), influenciada por los flujos migratorios de los últimos años ${ }^{13}$, ha ido creciendo en aquellas áreas donde tanto las condiciones laborales como económicas han sido mejores. La dinámica demográfica de la isla presentaba un flujo demográfico negativo en las primeras décadas del siglo XX, mientras que a partir de los años 80 este se torna positivo. La llegada de inmigrantes empezó a tener cierta importancia a partir de los años 70, siendo a finales del siglo XX cuando se dan los valores máximos.

Figura 3- Crecimiento poblacional de Menorca entre 1900 y 2010.

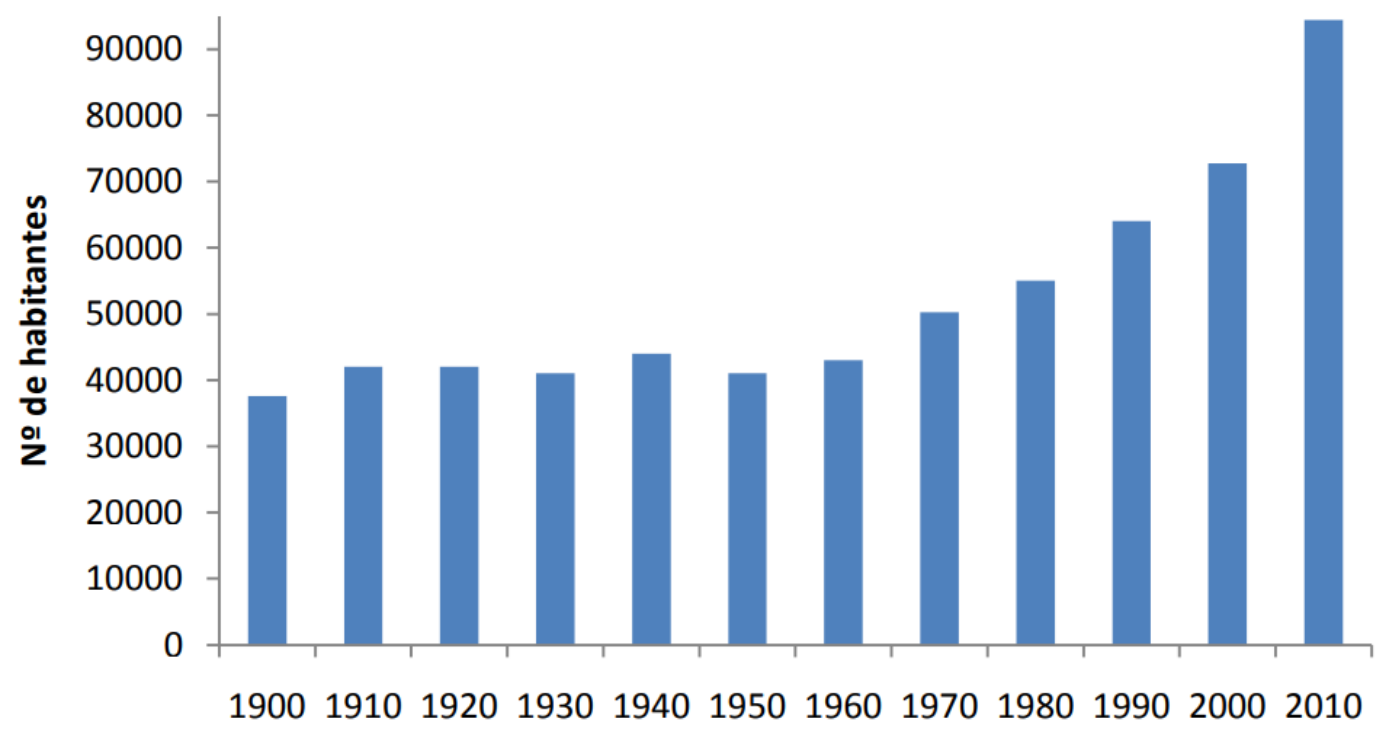

Año

Tanto a finales del siglo XX como a principios del siglo XXI, la actividad turística ha servido de atractivo para la llegada de población. La industria turística necesitaba de mucha mano de obra con el fin de poder ofrecer todo tipo de servicios, a lo que había que sumar el hecho de que la población menorquina era insuficiente para satisfacer la fuerte demanda de trabajadores, en su mayoría inmigrantes procedentes de otras comunidades autónomas. El resultante saldo migratorio positivo provocó un aumento considerable de la población, dando lugar a importantes pautas de comportamiento demográfico y social.

En otro orden de temas, y con el fin de ver el impacto que los CUS han producido sobre el DUS de Menorca, se han obtenido una serie de mapas (Fig. 4, 5, 6 y 7) por diferencia entre los valores de NDVI de la imagen correspondiente a la fecha fin y a la fecha inicio de cada lapso de tiempo considerado (1975/1990, 1990/2000, 2000/2005 y 2005/2010). En estos mapas, la mayoría de las áreas se encuentran en gris, indicando que no ha existido impacto alguno sobre el DUS a consecuencia de 


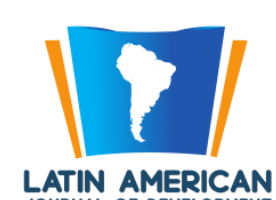

LATIN AMERICAN

que cada pixel tiene el mismo valor relativo en las fechas de inicio y fin. Por su parte, las áreas en verde indican que, en la fecha de inicio, las áreas construidas o alteradas son menores en superficie, mientras que los espacios mostrados en magenta indican que, en la fecha de fin, las superficies construidas o alteradas son menores en cuanto a extensión.

Figura 4- Impacto sobre el DUS entre 1975 y 1990.

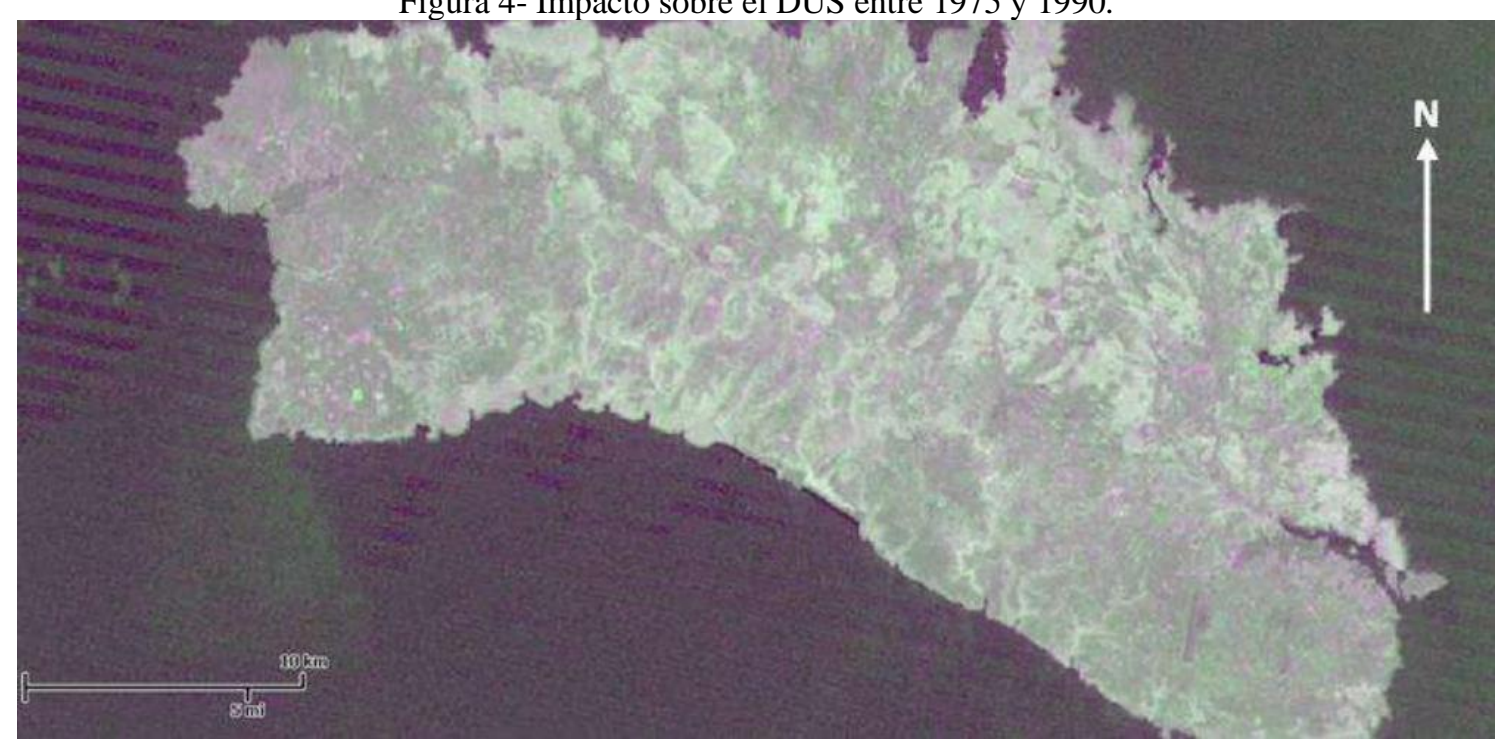

Figura 5- Impacto sobre el DUS entre 1990 y 2000.

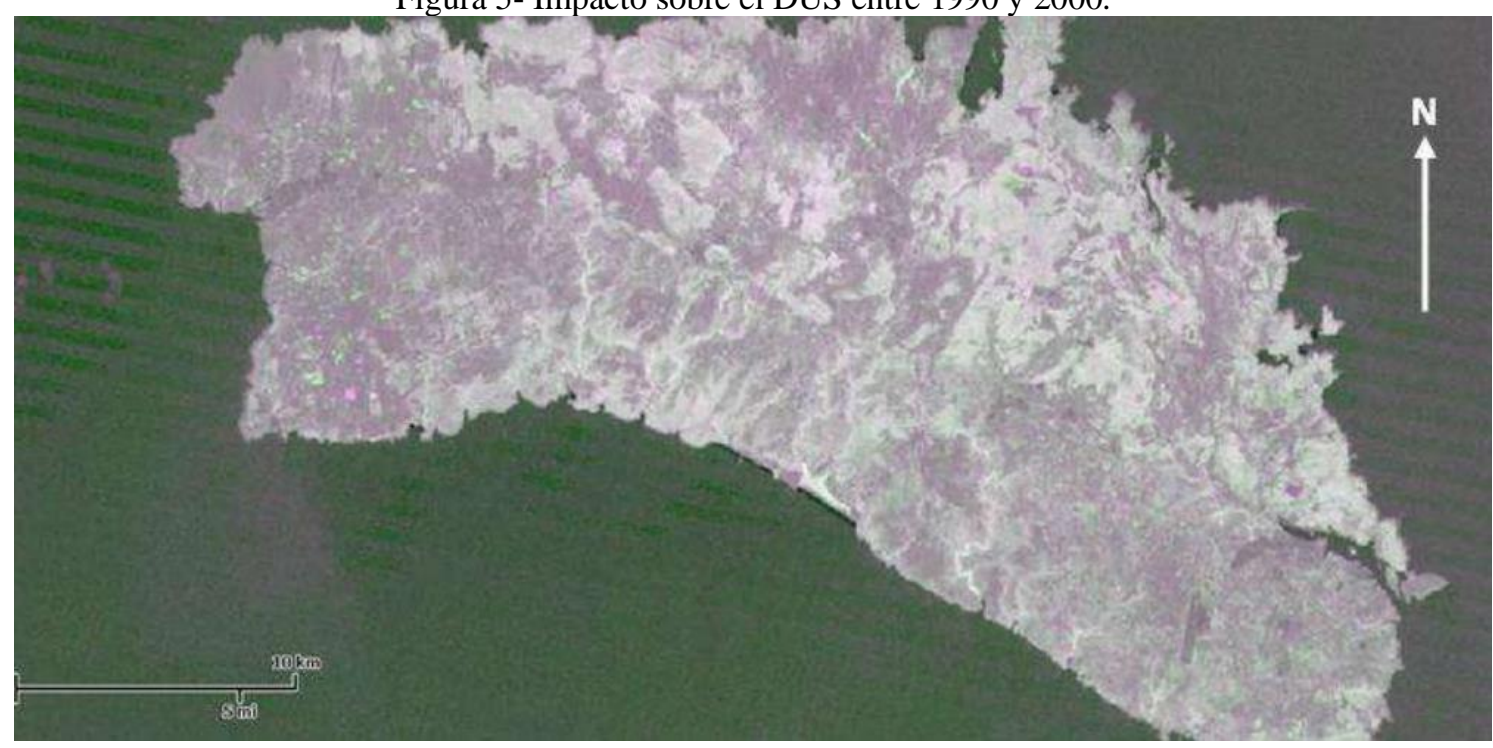

Tal y como podemos observar en las Fig. 4, 5, 6 y 7, el desarrollo del paisaje menorquín a principios de los 70 se encuentra estancado, probablemente ocasionado por la crisis económica internacional del periodo 1973-1975, momento en el que se inicia una tímida pero creciente construcción de infraestructuras hoteleras por el litoral insular. Posteriormente, entre 1975 y 1990, fecha esta última que desaceleró la economía a consecuencia de la Guerra del Golfo hasta 1993, se 
produjo una estabilización socioeconómica en la isla, lo que permitió consolidar las zonas turísticas que surgieron en el periodo anterior (áreas en gris de la Fig. 4), y la aparición de nuevas zonas con características urbanas de tipo extensivo, donde el tejido industrial era el principal soporte en dicho periodo. Sin embargo, y como respuesta a la crisis del Golfo, en la década de los 90 aparecieron nuevos atractivos turísticos de carácter ambiental (promoción del turismo en zonas no litorales), lo que dio lugar a una fuerte expansión de dicha actividad turística, no sólo por la aparición de la Ley de Espacios Naturales de 1991, sino también por la declaración de Menorca como Reserva de la Biosfera en 1993. Fue precisamente la falta de interacción entre las zonas del interior y del litoral lo que permitió que, tras el 8 de octubre de 1993, aparecieran políticas encaminadas a convertir el espacio insular en un territorio sostenible, dando lugar a la creación de nuevas infraestructuras y, por ende, a un incremento de presión sobre las recursos naturales (áreas en magenta de la Fig. 5).

Figura 6- Impacto sobre el DUS entre 2000 y 2005.

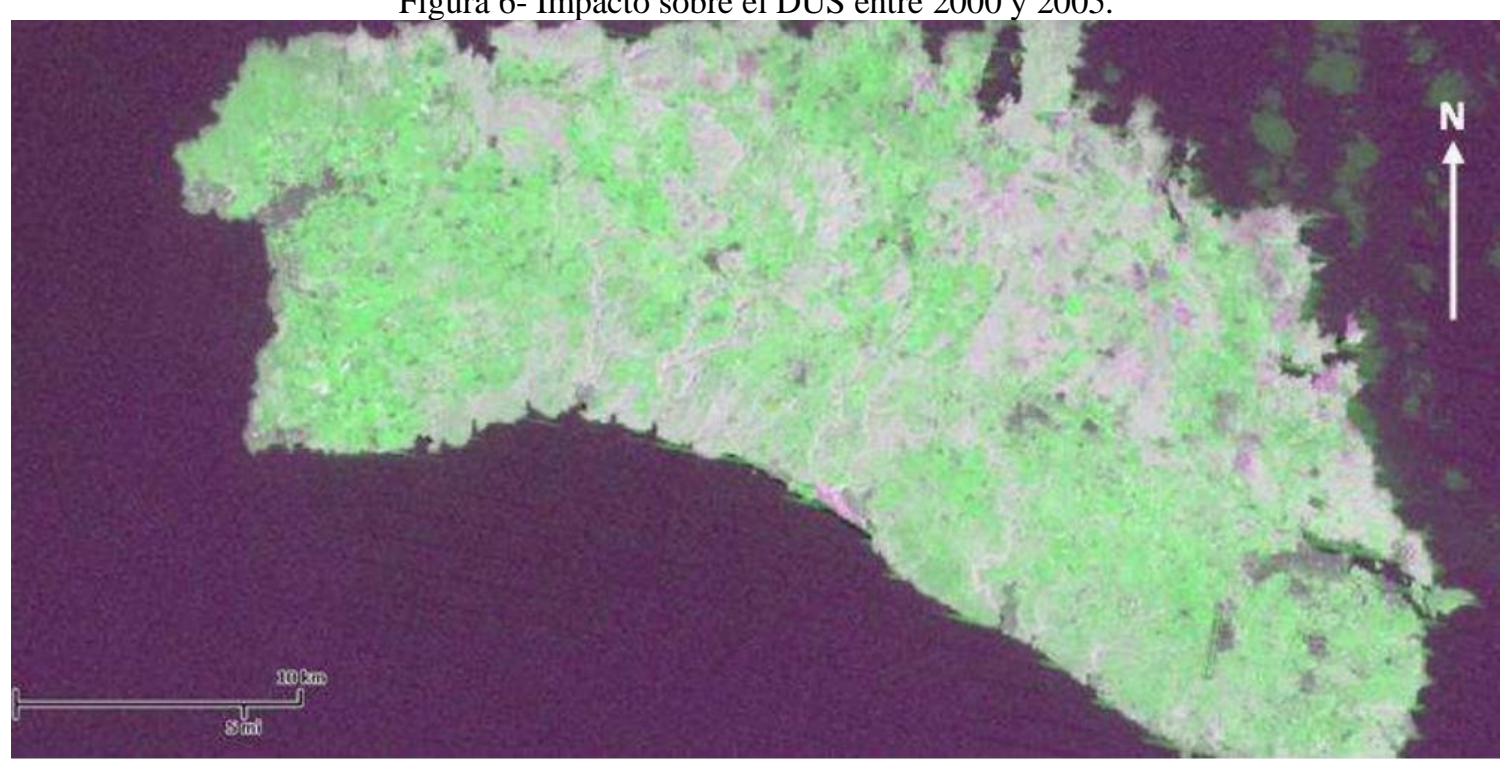


Figura 7- Impacto sobre el DUS entre 2005 y 2010.

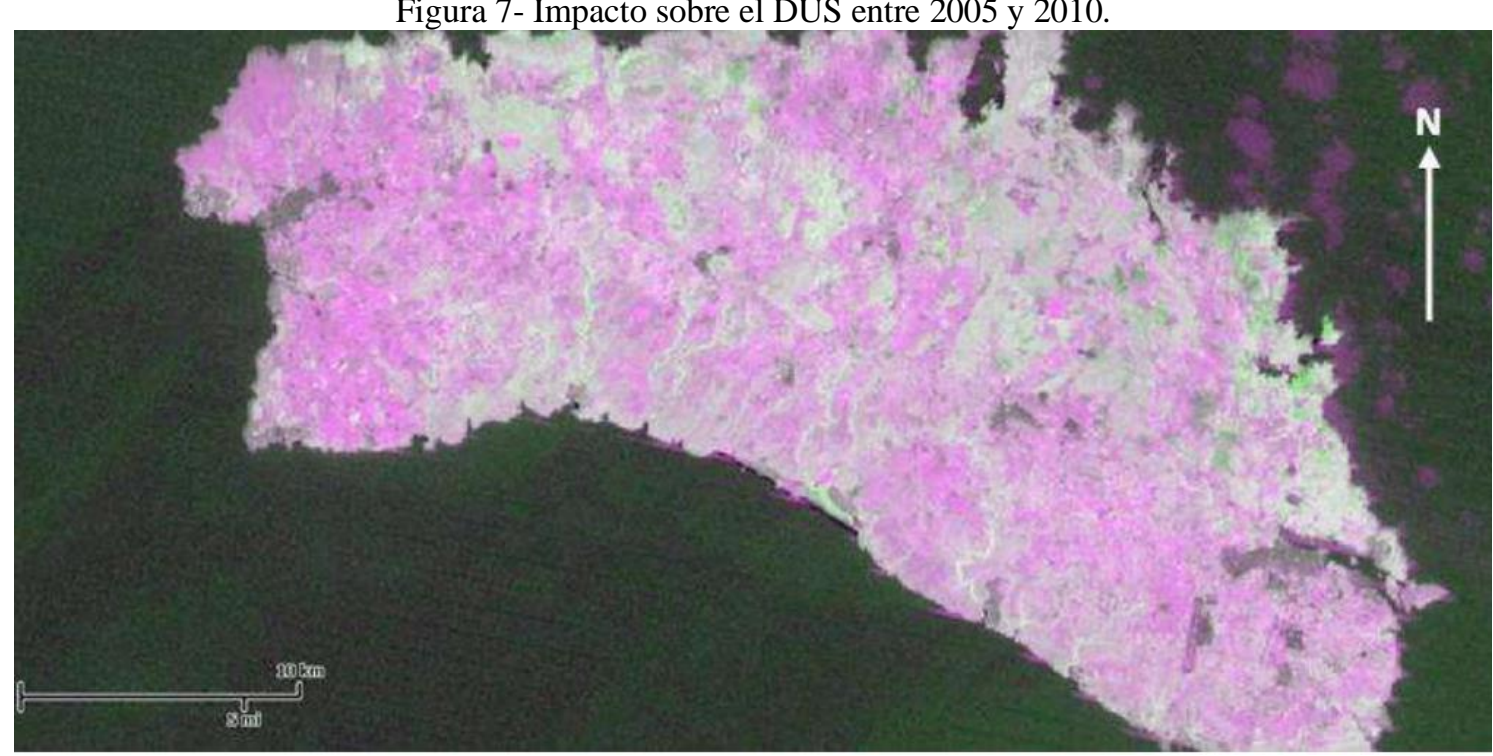

Por su parte, entre 2000 y 2005 las áreas en verde nos indican la existencia de un estancamiento en el desarrollo del territorio menorquín, quizás por la aprobación definitiva del PTI en 2003, motivo por el que debe de ser considerado este quinquenio como transitorio. Aun así, las áreas en gris de la Fig. 6 nos indicarían la existencia de pequeñas zonas de desarrollo difuso. Por último, y a consecuencia de los nuevos planes y acciones de sostenibilidad paisajística emprendidos por el Consell Insular de Menorca, puede observarse en la Fig. 7 como las áreas en magenta son predominantes, síntoma claro y evidente de que las medidas adoptadas están siendo las correctas, desempeñando un papel fundamental en el medio ambiente y la biodiversidad de la isla.

\section{CONCLUSIONES}

Si se compara los resultados obtenidos con la transformación tasseled cap realizada para la última década considerada (2000/2010), Fig. 8., se puede inferir que las áreas alteradas o construidas, indicadas ahora por el color rojo brillante, siguen el mismo patrón que el comentado, lo que ratifica lo especificado por [14] sobre la utilidad de la teledetección en este tipo de estudios. Las superficies con cierto tono verdoso no indican otra cosa que vegetación, mientras que las azuladas se refieren al grado de humedad del suelo. 
Figura 8- Transformación tasseled cap para la década 2000/2010.

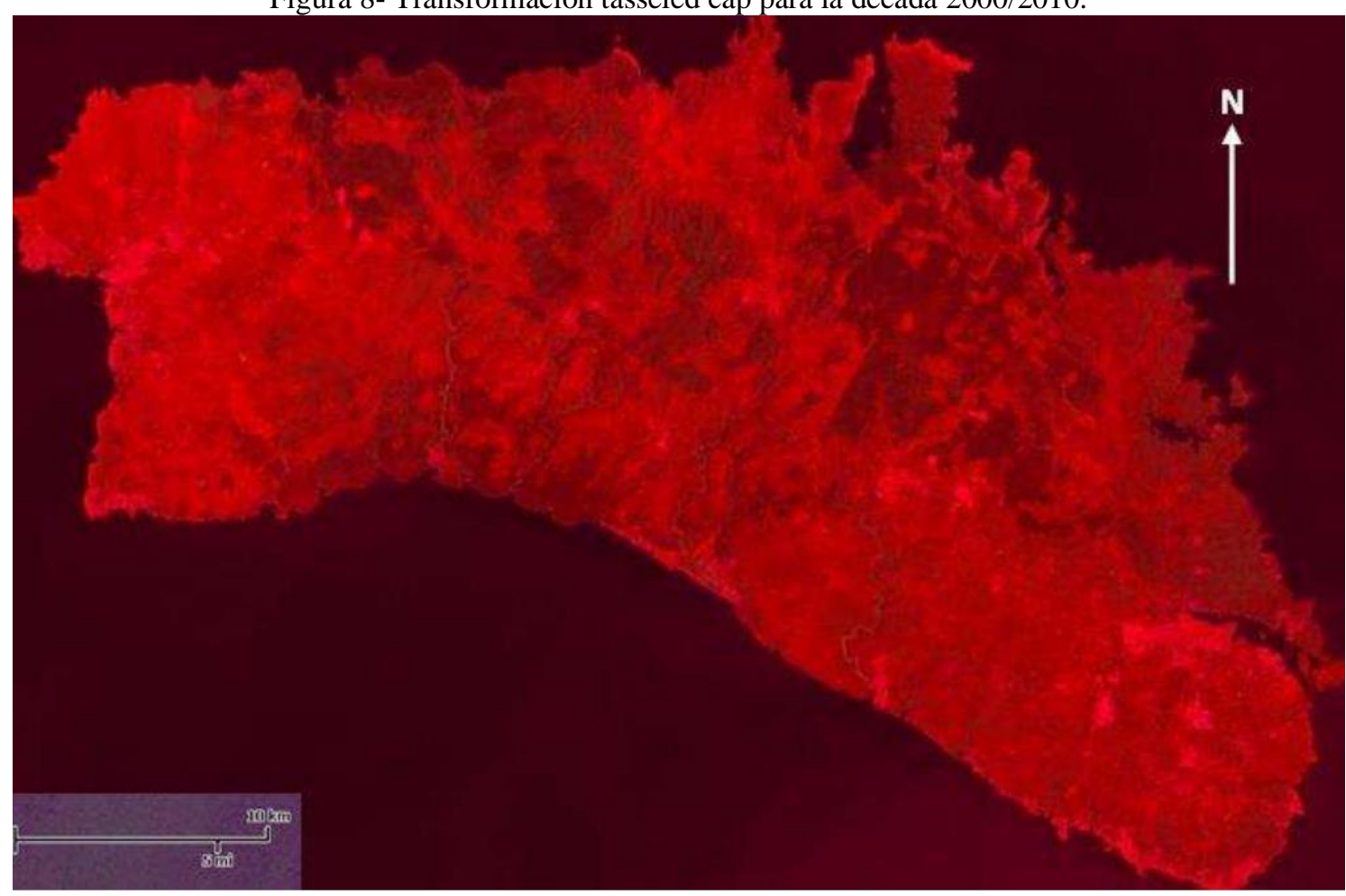

Con el presente trabajo se muestra la gran importancia que ha tenido el desarrollo histórico de Menorca en la actual conformación de su territorio, lo que, actualmente, ha originado la formación de una serie de islas dispersas por todo el espacio insular, cuyo carácter social propio e independiente de los sectores urbanos contiguos, han dado lugar a una serie de dinámicas locales y particulares de gran valor desde el punto de vista de la sostenibilidad. Además, el uso de la teledetección permite obtener la relación entre las diferentes dinámicas ${ }^{15}$ de forma precisa.

Respecto al DUS, habría que tener presente cada vez más la importancia de los polígonos industriales, ya que su correcta integración en el paisaje ${ }^{16}$ puede dar lugar al uso, plausible, de todavía más espacios abiertos, así como ciertas instalaciones orientadas a la comunidad. En relación a esto, la aplicación de las teorías imperantes sobre la ciudad del siglo XXI y los procesos de concertación social, que ayuden a la configuración de un escenario territorial con nuevas reglas del juego, son los puntos a tener en cuenta para lograr la consideración del paisaje urbano como un argumento lícito para el desarrollo local, el bienestar social y la mejora de la calidad de vida de los ciudadanos en el marco de los criterios de sostenibilidad. 


\section{REFERENCIAS}

1. Olcina Cantos, J. (2020). El litoral mediterráneo español, territorio de riesgo. Mediterráneo Económico, 33:197-212.

2. Mata Olmo, R., Rodríguez Esteban, J.A. y Sevilla Callejo, M. (2002). "Un SIG para el Plan de Ordenación de Menorca. Aspectos ambientales y paisajístico", X Congreso de Métodos Cuantitativos, SIG y Teledetección. Valladolid, Universidad de Valladolid-AGE, p. 1-12.

3. Institut d'Estadística de les Illes Baleaars. (2021). Resumen demográfico. Datos definitivos. [Internet]. Acceso (06:10:2021). https://ibestat.caib.es/ibestat/inici

4. Precedo Ledo, A., Míguez Iglesias, A. y Orosa Gonzáalez, J. (2012). “The management and planning of supra-municipal spaces: from the metropolitan areas to the urban regions", 32nd Congress of the International Geographical Union. Cologne, Germany, Instituto Geográfico Nacional (Eds.), p. 570579.

5. Yrigoy, I. (2017). Airbnb en Menorca: ¿una nueva forma de gentrificación turística?: localización de la vivienda turística, agentes e impactos sobre el alquiler residencial. Scripta Nova, XXI(580): 131 .

6. Bauzà Van Slingerlandt, A. (2006). "Menorca... is different", VIII Coloquio y Jornadas de Campo de Geografía Urbana, Islas Baleares. Universitat de les Illes Balears-AGE, p. 76-106.

7. Santos Preciado, J.M., Azcárate Luxán, M.A., Cocero Matesanz, D., García Lázaro, F.J. y Muguruza Cañas, C. (2012). “Claves del crecimiento urbano actual”. En Gómez Delgado, M. y Rodríguez Espinosa, V.M. (coord.): Análisis de la dinámica urbana y simulación de escenarios de desarrollo futuro con tecnologías de la información geográfica. RA-MA editorial, p. 19-78.

8. Ramírez-Juidías, E. y Víquez-Urraco, F. (2013). "Cambios en el paisaje de Menorca desde 1975 hasta 2010 mediante imágenes teledetectadas", XXIII Congreso de Geógrafos Españoles: Espacios insulares y de frontera, una visión geográfica. P. 447-457.

9. Aguayo Ramírez, A. (2018). Estudio mediante teledetección del litoral de Doñana: influencia del dique Juan Carlos I sobre la morfología de la costa y las poblaciones vegetales del sistema dunar. Tesis de Máster en Ingeniería de Caminos Canales y Puertos. Universidad de Sevilla. https://idus.us.es/handle/11441/81746.

10. Ramírez-Juidías, E., Tejero-Manzanares, J., Moreno-Fresno, J.J., Justicia-Segovia, M., MadueñoLuna, A. y López-Lineros, M. (2015). "Land use changes and volumetric processes in the Tinto saltmarshes", Proceedings of the 2015 AASRI International Conference on Circuits and Systems, p. 105108.

11. Jensen, J.R. (2005): Introductory digital image processing: a remote sensing perspective. New Jersey, Prentice Hall, 526 p.

12. AEMET e Instituto de Meteorología de Portugal. (2011). Atlas climático ibérico: temperatura del aire y precipitación (1971-2000). Madrid, Ministerio de Medio Ambiente y Medio Rural y Marino, 79 p. 
13. Fullana Coll, A. (2005). Evolución de la población de Menorca a finales del siglo XX. Incidencia de la actividad turística en su desarrollo. Cuadernos Geográficos, 36: 307-317.

14. Avtar, R., Komolafe, A.A., Kouser, A., Singh, D., Yunus, A.P., Dou, J., Kumar, P., Das Gupta, R., Johnson, B.A., Thu Minh, H.V., Aggarwal, A.K. y Kurniawan, T.A. (2020). Assessing sustainable development prospects through remote sensing: a review. Remote Sensing Applications: Society and Environment, 20: 100402.

15. Simpson, C.E., Arp, C.D., Sheng, Y., Carroll, M.L., Jones, B.M. y Smith, L.C. (2020). Remote sensing of lake wáter volumes on the Artic Coastal Plain of Northern Alaska. Earth System Science Data, 1-21.

16. Romano. L., Quintana de Castro, G. y Huber, M. (2021). Intervention in the urban heritage: the case of the discipline of architecture, urbanism and landscaping workshop IX-CAU/UFSM. Latin American Journal of Development, 3(4): 2240-2254. 